\title{
A combined 3D surveying, XRF and Raman in-situ investigation of The Conversion of St Paul painting (Mdina, Malta) by Mattia Preti
}

\author{
Sebastiano D’Amico ${ }^{1}$, Valentina Venuti ${ }^{2}$, Emanuele Colica ${ }^{1}$, Vincenza Crupi $^{3}$, Giuseppe Paladini ${ }^{2}$, Sante \\ Guido $^{4}$, Giuseppe Mantella ${ }^{5}$, Domenico Majolino² \\ ${ }^{1}$ Department of Geosciences, University of Malta, Msida Campus, MSD 2080, Malta \\ 2 Department of Mathematical and Computer Sciences, Physical Sciences and Earth Sciences, University of Messina, Viale Ferdinando \\ Stagno D'Alcontres 31, I-98166 Messina, Italy \\ ${ }^{3}$ Department of Chemical, Biological, Pharmaceutical and Environmental Sciences, University of Messina, Viale Ferdinando Stagno \\ D’Alcontres 31, I-98166 Messina, Italy \\ ${ }^{4}$ Department of Literature and Philosophy, University of Trento, Via Tommaso Gar, 14, I-38122 Trento, Italy \\ ${ }^{5}$ Giuseppe Mantella Restauro Opere D’Arte, Circonvallazione Paparo 25, Isca sullo Ionio, (CZ) 88060, Italy
}

\section{ABSTRACT}

This paper presents the results of three different approaches applied to the newly-restored titular painting entitled The Conversion of St Paul, the main altarpiece in the Mdina Cathedral in Malta. This large, dramatic painting is the work of the Baroque artist, Mattia Preti, known as il Cavaliere Calabrese. Here, we focus on the results of the digital photogrammetric survey that adopts image-based approaches for 2D/3D model reconstruction. The model was used to quantify important features of the painting as well extensions of the areas restored. In addition, portable X-ray fluorescence and Raman spectroscopies were used to non-destructively identify the nature of the painting materials, at the elemental and molecular spatial scales, respectively, with the ultimate goal of reconstructing the colour palette of the artist. The 3D model developed here could be applied to other paintings of Preti to conduct comparisons between different measurements in the paintings, with the main goal of clarifying the technique used by the artist. This information, along with the characterisation of the materials used, is crucial for the reconstruction of the historical-geographical context of the artwork, since specific pigmenting agents and media tend to represent the stylistic expression of an artist or an epoque.

Section: RESEARCH PAPER

Keywords: 'The Conversion of St Paul' painting; photogrammetry; XRF; Raman; pigment identification

Citation: Sebastiano D'Amico, Valentina Venuti, Emanuele Colica, Vincenza Crupi, Giuseppe Paladini, Sante Guido, Giuseppe Mantella, Domenico Majolino, A combined 3D surveying, XRF and Raman in-situ investigation of The Conversion of St Paul painting (Mdina, Malta) by Mattia Preti, Acta IMEKO, vol. 10, no. 1, article 23, March 2021, identifier: IMEKO-ACTA-10 (2021)-01-23

Editor: Ioan Tudosa, University of Sannio, Italy

Received April 28, 2020; In final form November 4, 2020; Published March 2021

Copyright: This is an open-access article distributed under the terms of the Creative Commons Attribution 3.0 License, which permits unrestricted use, distribution, and reproduction in any medium, provided the original author and source are credited.

Corresponding author: Valentina Venuti, e-mail: vvenuti@unime.it

\section{INTRODUCTION}

In recent years, the use of scientific methods to help with the restoration of artifacts has attracted a great deal of interest [1][4]. Here, as testified by the increasing number of recent publications related to three-dimensional (3D) documentation and reconstruction [5], the use of software and various techniques to reconstruct digital models of the artifacts has grown significantly in view of providing useful tools for conservation and cultural heritage documentation, as well as the integration of scientific analysis and results. Specifically, the possibility of generating highly accurate and detailed 2D/3D digital models from existing imagery presents a great opportunity for analysis, with various applicable tools available. Meanwhile, X-ray fluorescence (XRF) spectroscopy represents a wellestablished, rapid and simple to use non-destructive method that allows for determining the elemental composition of the pigmenting agents of decorated surfaces [6]-[9]. This technique is often used in conjunction with another versatile technique, namely, Raman spectroscopy, to achieve the molecular composition of pigments in a non-destructive manner, which is 
mandatory, especially when dealing with pigments of similar atomic composition and/or mixtures of pigments that are difficult to disentangle. The combined use of these two techniques allows for addressing various questions related to provenance, dating, and the manufacturing technology behind a variety of findings [10].

Furthermore, in the case of large valuable paintings held in public collections, any form of sampling is discouraged by the curators and conservators. As such, an in-situ approach that requires the spectrometric investigation to be extended into the historical/artistic context is strongly recommended.

In this paper, we present the main results obtained via three different approaches, namely, digital photogrammetry, portable XRF spectroscopy, and Raman spectroscopy, all of which were used to help with the restoration of the titular painting entitled The Conversion of St Paul, which is located above the main altar at St Paul's Cathedral in Mdina, Malta (Figure 1) [11]. The author of this grand canvas, which measures $533 \times 310 \mathrm{~cm}$, was Mattia Preti, known as il Cavaliere Calabrese. Preti worked on this masterpiece in 1682 having been commissioned to execute the painting by the bishop of Malta, the Catalan Miguel Jeronimo de Molina y Aragonès, a member of the Knights of the Order of Malta, whose coat-of-arms is painted on the column of the righthand side of the painting.

The Conversion of St Paul relates to the series of miracles and mysteries pertaining to Malta's St Paul's. In fact, this was the subject of a major cycle of paintings executed by Mattia Preti towards the end of his life during the last decades of the $17^{\text {th }}$ century.

Given its size, the painting can be regarded as the masterpiece among the work completed by Preti during his long stay in the Maltese archipelago. It describes the moment when the young Roman soldier, Saulo, was struck blind by the thunderbolt vision of Christ when on his way to Damasco, whereupon he fell from his horse (event never actually mentioned in the Bible) and remained blind for three days.

The recent restoration of The Conversion of St Paul indicated that it was single-handedly painted by the master, without the collaboration of any of his assistants. The original painting is perfectly rectangular and was created by joining three pieces of canvas of equal size. The painting also features two enlargements, the first of which measures around $5 \mathrm{~cm}$ in width with the colours painted directly onto the canvas without a preparatory underlay made of oils, globigerina powder, and ochre. Meanwhile, the second enlargement is dated to the first part of the XVIII century and sees the addition of a new strip of canvas with a height of $50 \mathrm{~cm}$ that follows the profile of the new marble frame. The whole surface was covered by a thick layer of extremely greasy yellow/brown paint that altered the entire chromatic relationship. During the cleaning phase, the original Testaferrata coat-of-arms, which had been hidden when the painting underwent a lengthening process, was revealed. Consolidation was carried out and several gaps were repaired with stucco, while retouching was performed and the surface was given a transparent protective film.

Motivated by the historical/artistic value of the restoration, we decided to deepen the investigation of the painting using portable equipment, combining a high-performance 3D laser scanning system for surveying with the aforementioned noninvasive XRF and Raman spectroscopic techniques. Here, the first technique was used for reconstruction purposes, while the latter two techniques were used for pigment characterisation, with the ultimate aim of obtaining useful information regarding certain questions that remain unaddressed, which are largely related to the execution technique and to the dating of the Maltese period in which the painting was produced.

\section{DATA AQUISITION AND PROCESSING}

The various modern technological solutions offer great opportunities to obtain complete geomatic surveys in various environments [12] and in the field of cultural heritage [2], [13], [14]. Here, photogrammetry can be defined as a scientific pursuit aimed at obtaining reliable information regarding the spatial properties of land surfaces and objects, without the need for physical contact [15]. It presents a relatively new technique for the accurate digital capturing of 3D objects and surfaces, and has become increasingly popular within the conservator community,
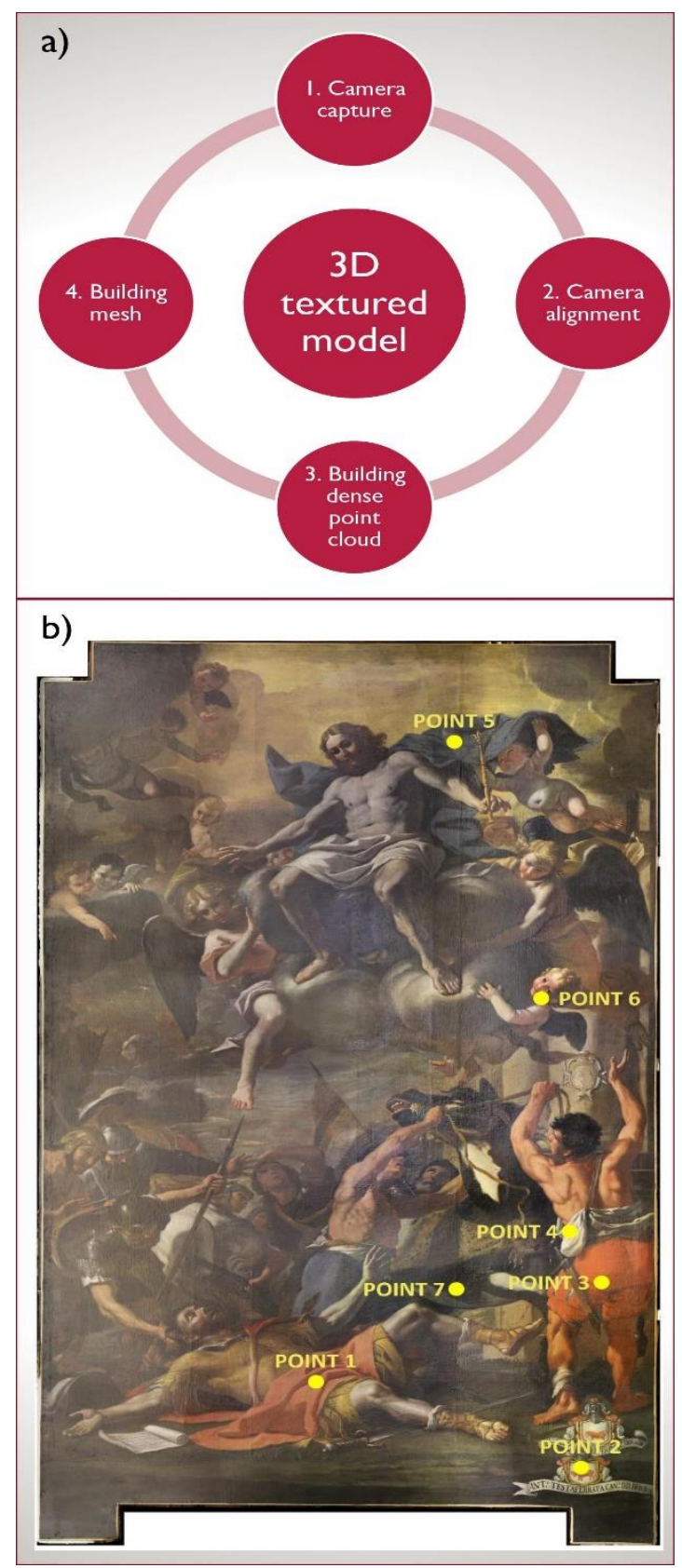

Figure 1. a) Workflow adopted to obtain the final digital model for The Conversion of St Paul painting. b) The painting reconstructed using digital technologies and processing. All points analysed via XRF and/or Raman spectroscopy are displayed. 
often adopted in the field of cultural heritage as a set of new tools for archaeologists and experts working in this area. The method has the great advantage of having the capacity to capture, store, process, share, visualise and annotate $2 \mathrm{D} / 3 \mathrm{D}$ objects. Figure $1 \mathrm{a}$ presents the workflow adopted to obtain the final digital model for The Conversion of St Paul painting, which consisted of several phases of processing. The first phase (steps 1 and 2) involved the camera capturing and alignment, which allowed for correctly placing the images in relation to each other and/or calculating the exact position in the real space. It is at this stage that the software generates a sparse point cloud. Meanwhile, the second phase (step 3) involved the generation of a dense point cloud based on the estimated camera positions. If required, the dense cloud of points can be modified prior to the generation of the 3D mesh model. The third phase (step 4) involved the reconstruction of a $3 \mathrm{D}$ polygonal mesh representing the object surface, as based on the dense point cloud. Following the mesh geometry generation and reconstruction, the model was textured and used for orthomosaic generation.

Figure $1 \mathrm{~b}$ shows the final digital model of the painting and the location of the pigments analysed via XRF and Raman spectroscopy. Here, the XRF measurements were carried out using a portable XRF Alpha 4000 analyser (Innovex-X system), which allows for the detection of chemical elements with an atomic number $(Z)$ between phosphorus and lead and is equipped with a Ta anode X-ray tube as the source and a Si PIN diode (active area of $170 \mathrm{~mm}^{2}$ ) as the detector. The instrument was operated in soil mode, with a Compton normalisation algorithm designed for achieving the lowest possible limit of detection (LOD) (trace concentrations, ppm levels) for soil and bulk samples. The soil mode was used with the 'environmental' elements suite, which includes the following elements: $\mathrm{P}, \mathrm{S}, \mathrm{Cl}$, $\mathrm{K}, \mathrm{Ca}, \mathrm{Ti}, \mathrm{Cr}, \mathrm{Mn}, \mathrm{Fe}, \mathrm{Co}, \mathrm{Ni}, \mathrm{Cu}, \mathrm{Zn}$, As, Se, Br, Rb, Sr, Zr, Mo, $\mathrm{Ag}, \mathrm{Cd}, \mathrm{Sn}, \mathrm{Sb}, \mathrm{I}, \mathrm{Ba}, \mathrm{Au}, \mathrm{Hg}, \mathrm{Pb}$. For each sample, two sequential tests were performed, the first with operating conditions of $40 \mathrm{kV}$ and $7 \mu \mathrm{A}$ and the second with conditions of $15 \mathrm{kV}$ and $5 \mu \mathrm{A}$, for a total spectrum collection time of $120 \mathrm{~s}$. The instrument was controlled by a Hewlett-Packard iPAQ Pocket PC, which was also used for the data storage. The calibration was performed using a soil light element analysis program (LEAP) II and was verified using alloy certified reference materials produced by Analytical Reference Materials International. To obtain better statistics, a fluorescence signal was collected for $60 \mathrm{~s}$ per run. For all the investigated samples, the lines detected at around 8.15 and $9.34 \mathrm{keV}$ were attributed to the $\mathrm{L}_{\alpha}$ and $\mathrm{L}_{\beta}$ transitions of the Ta anode.

Meanwhile, the Raman spectra were collected using a portable 'BTR 111 Mini-RamTM' (B\&W Tek, USA) spectrometer with an excitation wavelength of $785 \mathrm{~nm}$ (diode laser) and a maximum laser power of $280 \mathrm{~mW}$ at the excitation port, and a chargecoupled device (CCD) detector (thermoelectric cooled, TE). Here, the laser output power can be continuously adjusted by maximising the signal-to-noise ratio while minimizing the integration time, while the system is equipped with a fibre optic interface for convenient sampling. The excitation laser emits from the probe's end, where the Raman signal is then collected from the sample. The spot size was $85 \mu \mathrm{m}$ at a working distance of $5.90 \mathrm{~mm}$. The maximum power at the samples was around 55 $\mathrm{mW}$. All the spectra were registered in the wavenumber range of $60-3,150 \mathrm{~cm}^{-1}$ by using an acquisition time of $40 \mathrm{~s}$ and a resolution of $8 \mathrm{~cm}^{-1}$ while accumulating several scans for each spectrum in order to improve the signal-to-noise ratio. Each spectrum was processed by subtracting the blank spectrum, while a smoothing process was performed using BWSpec 3.27 software. Meanwhile, the assignment of the Raman vibrational bands, which was aimed at identifying the used materials, was performed with reference to the relevant databases and libraries [16], [17].

\section{RESULTS AND DISCUSSION}

The digital model of the painting allowed for obtaining high precision measurements of the artifact as a whole as well as of selected areas of interest. Figure 2 and Figure 3 show examples of the measurements of selected areas as well as the distances between selected points. Specifically, Figure 3 shows details of the coat-of-arms in the painting, where two coat-of-arms can be clearly observed. The lower one was added at a later stage when the painting was slightly enlarged to fit a new frame, while the one above, which was previously hidden, was recovered during the restoration works. Using the digital model, we were able to map and measure two parts of both coat-of-arms, highlighting the difference in shape and size between them with high precision, that is, with a spatial resolution of the order of millimetres, which is much lower than that of traditional analogical methods.

It is worth noting that photogrammetry is an extremely useful tool both for the pre-restoration phase and for further studies and investigations. In fact, such an approach could help historians and conservators to plan any necessary interventions, or to study details of the painting while using the digital model, and, as such, without touching or directly interacting with the artifact. Furthermore, the digital model can be used for mapping purposes, as was the case in this study, by inserting certain points of measurements in the model. Finally, it is also possible to create a digital repository of historical and scientific information that could be easily consulted remotely. Both these tools and the

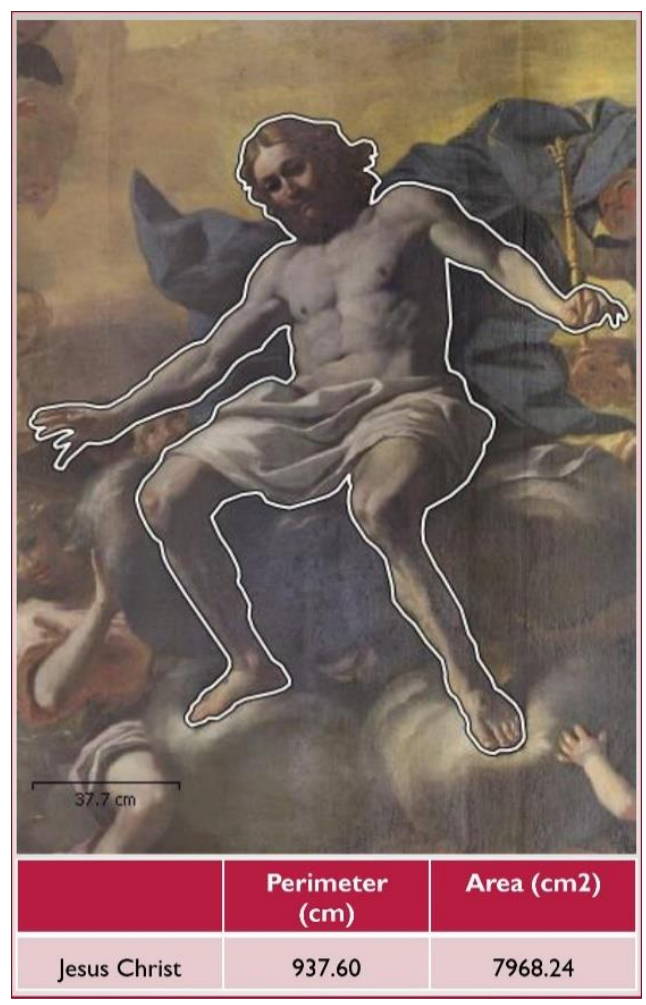

Figure 2. Details of the digital model of the painting, which highlights the high definition of the model. The table below presents some of the measurements taken from it. 


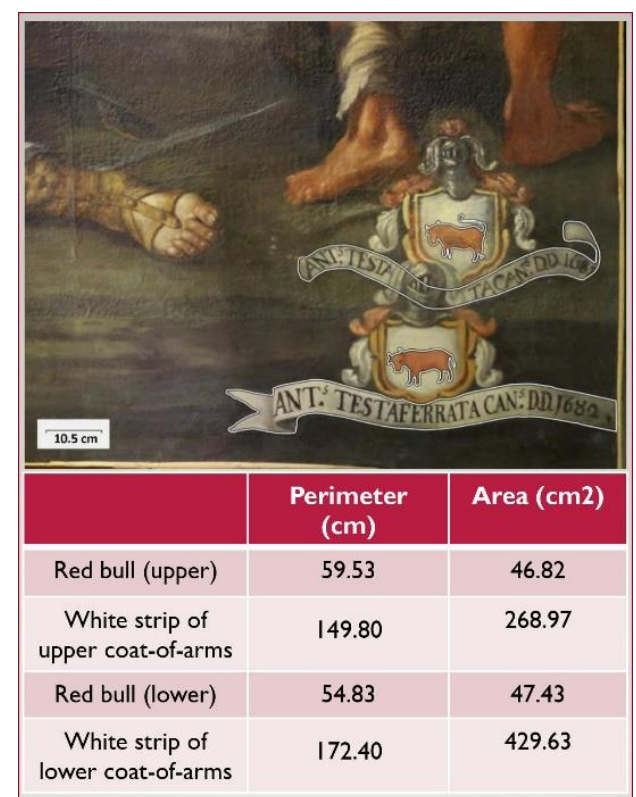

Figure 3. Example of measured areas and lengths of two parts of the coat-ofarms depicted in the painting.

digital model could be combined with modern vision equipment to bring the painting into the virtual reality context, which has endless applications and uses.

With the aim of identifying the pigmenting agents used for the different colours and tonalities of the Conversion of St Paul painting, seven points were selected for XRF and/or Raman analyses (see Figure 1) with some consideration of the short time available for the restoration and for the exhibition preparation. Table 1 presents the entire set of performed measurements as well as the elemental and molecular composition, obtained via the XRF and Raman techniques, respectively. Meanwhile, Figure 4 presents the XRF spectra collected for the red cloth of the lying soldier (point 1, Figure 4a), the white band of the soldier standing upright (point 4, Figure 4b), the blue area of Christ's mantle (point 5, Figure 4c), and the black fur of the horse (point 7 , Figure 4d) as examples.

The XRF analysis for all the investigated red/reddish areas (points 1, 2, 3, and 6, see Figure $4 \mathrm{a}$ for the representative spectrum) indicated a $\mathrm{Hg}$-based red pigment, likely cinnabar $(\mathrm{HgS})$, which was used for the vestments, coat-of-arms, and carnations. Traces of iron $(\mathrm{Fe})$ were also detected, suggesting the use of a small amount of red ochre $\left(\mathrm{Fe}_{2} \mathrm{O}_{3}\right)$. Pigmenting agents were likely combined with a white $\mathrm{Pb}$-based composite, possibly lead white $\left(\left[\mathrm{PbCO}_{3}\right]_{2} \cdot \mathrm{Pb}[\mathrm{OH}]_{2}\right)$, to obtain a lighter tonality. The relative intensity of the peaks corresponding to the
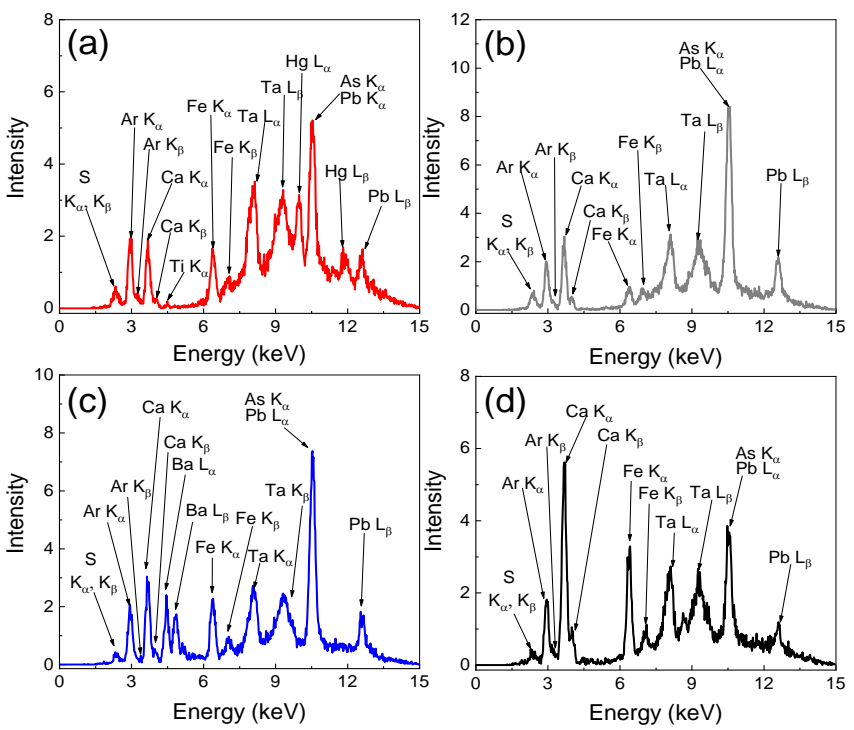

Figure 4. XRF spectra collected (a) on the red cloth of the lying soldier (point 1), (b) on the white band of the soldier standing upright (point 4), (c) on the blue area of Christ's mantle (point 5), and (d) on the black fur of the horse (point 7).

aforementioned elements differed depending on the desired shades.

With regard to the white area (point 4, Figure $4 \mathrm{~b}$ ), the observation of the high peaks associated with the $\mathrm{L} \alpha$ (around $10.54 \mathrm{keV}$ ) and $\mathrm{L}_{\beta}$ (around $12.60 \mathrm{keV}$ ) transition lines of lead $\mathrm{Pb}$ ) indicated the use of a Pb-based white pigmenting agent, possibly lead white, largely responsible for the white coloration.

Despite its toxicity, this white pigment was widely used in panel paintings due to its good covering potential and brilliant white colour.

In terms of the XRF spectrum of the blue area (point 5, Figure 4c), no characterising lines were detected. Here, the traces of Fe, manganese $(\mathrm{Mn})$ and zinc $(\mathrm{Zn})$ could be due to the impurities that gradually emerged, which could support the notion of the use of an organic compound that cannot be detected via XRF since its characterising elements are lighter than those revealed by this technique. Based on a comparison with findings in the existing literature [18], the application of indigo $\left(\mathrm{C}_{16} \mathrm{H}_{10} \mathrm{~N}_{2} \mathrm{O}_{2}\right)$ for the blue coloration would appear to be the most reasonable hypothesis, certainly given that the presence of this natural blue pigmenting agent has previously been identified in other religious paintings produced by Preti during his later activity in Malta [19]. Here, it is worth noting that the presence of barium $(\mathrm{Ba})$ could suggest the use of barium sulphate $\left(\mathrm{BaSO}_{4}\right)$, i.e. 'barium white', a synthetic compound used as a pigment, extender and filler since the early part of the 19th century [20], thus indicating that

Table 1. Elemental and molecular phases of the selected areas of The Conversion of St Paul, detected via XRF and Raman spectroscopy, respectively. The key elements responsible for the analysed pigments are marked in bold, while the minor and trace elements are reported in brackets.

\begin{tabular}{|c|c|c|c|}
\hline Analysed point & Description of the analysed area & XRF elements & Detected Raman phase \\
\hline 1 & Red cloth of the lying soldier & $\mathrm{S}, \mathrm{Pb}, \mathrm{Ca}, \mathrm{Hg},(\mathrm{Cl}, \mathrm{As}, \mathrm{K}, \mathrm{Fe}, \mathrm{Se}, \mathrm{Sb})$ & Cinnabar, iron oxides, calcite \\
\hline 2 & Red bull of the coat-of-arms located at the bottom right & $\mathrm{S}, \mathrm{Pb}, \mathrm{Cl}, \mathrm{As}, \mathrm{Fe}, \mathrm{Ca}, \mathrm{K}, \mathrm{Hg}$, (Sn, Cd) & Cinnabar, iron oxides \\
\hline 3 & Red robe of the soldier standing upright & $\mathrm{S}, \mathrm{Pb}, \mathrm{Cl}, \mathrm{As}, \mathrm{Fe}, \mathrm{Ca}, \mathrm{K}, \mathrm{Hg}, \mathrm{Se},(\mathrm{Mn}, \mathrm{Rb})$ & Cinnabar, iron oxides, calcite \\
\hline 4 & White band of the soldier standing upright & $\mathrm{S}, \mathrm{Pb}, \mathrm{Ca}, \mathrm{Cl},(\mathrm{As}, \mathrm{K}, \mathrm{Fe}, \mathrm{Co}, \mathrm{Zn})$ & Lead white, calcite \\
\hline 5 & Blue area of Christ's mantle & $\mathrm{S}, \mathrm{Pb}, \mathrm{Ca}, \mathrm{Cl}, \mathrm{Ba},(\mathrm{As}, \mathrm{Fe}, \mathrm{Mn}, \mathrm{Zn}, \mathrm{Sr})$ & Fluorescence \\
\hline 6 & $\begin{array}{l}\text { Reddish area of the incarnate of } \\
\text { the cheeks of the little angel }\end{array}$ & $\mathrm{S}, \mathrm{Pb}, \mathrm{Cl}, \mathrm{As}, \mathrm{Fe}, \mathrm{Ca}, \mathrm{K}, \mathrm{Hg}, \mathrm{Se},(\mathrm{Cd}, \mathrm{Mn}, \mathrm{Zn}, \mathrm{Rb})$ & Cinnabar, iron oxides, calcite \\
\hline 7 & Black fur of the horse & $\mathrm{S}, \mathrm{Ca}, \mathrm{Pb}, \mathrm{Cl},(\mathrm{K}, \mathrm{As}, \mathrm{Fe}, \mathrm{Ba}, \mathrm{Zn}, \mathrm{Mn}, \mathrm{Cu})$ & Carbon black \\
\hline
\end{tabular}


modern paints were applied to the panel surface during previous restorations.

Finally, in the case of the black area (point 7 , Figure $4 d$ ), the high peaks of calcium (Ca), together with the observation of $\mathrm{Fe}$ and $\mathrm{Mn}$, allowed us to hypothesise about the use of an organic black pigment, based on $\mathrm{Ca}$, one that cannot be confirmed by $\mathrm{XRF}$ due to the low $Z$-value of the characteristic elements, combined with a mixture of Fe-based and $\mathrm{Mn}$-based pigments, such as natural and/or burned umber $\left(\mathrm{Fe}_{2} \mathrm{O}_{3}+\mathrm{MnO}_{2}+\mathrm{nH}_{2} \mathrm{O}\right.$ $\left.+\mathrm{Si}+\mathrm{Al}_{2} \mathrm{O}_{3}\right)$.

In addition, it is worth noting that an important presence of $\mathrm{Ca}$, sulphur $(\mathrm{S})$, and $\mathrm{Pb}$ was observed in all the investigated areas. Given their presence, these substances were likely related to the preparatory layer, suggesting a Ca-based preparation ground that was possibly calcium carbonate $\left(\mathrm{CaCO}_{3}\right)$ and/or sulphate $\left(\mathrm{CaSO}_{4}\right)$. In terms of the detection of $\mathrm{Pb}$, its presence in every analysed point supports the hypothesis regarding the employment of a Pb-based imprimation, likely made of lead white, could also have been used as a dryer for the binders.

With regard to the Raman measurements, we must first focus on the results of the analysis performed on points 2, 3 and 6 of the painting (Figure 5), that is, the areas of the red bull of the coat-of-arms located at the bottom right (a), the red robe of the soldier standing upright (b), and the reddish area of the incarnate of the cheeks of the little angel (c), respectively. Since the Raman spectrum obtained for point 1 was highly similar to those reported in Figure 5, it is not shown.
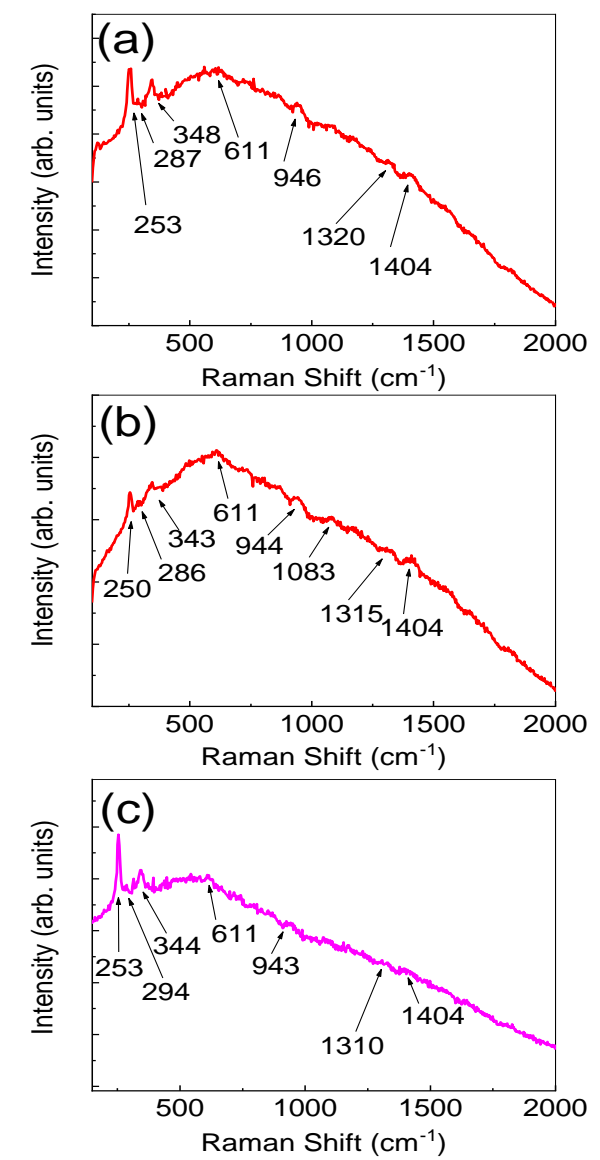

Figure 5. Raman spectra recorded for three representative red/reddish pigmented areas of The Conversion of St Paul painting. (a) Red bull of the coat-of-arms located at the bottom right (point 2), (b) red robe of the soldier standing upright (point 3), (c) reddish area of the incarnate of the cheeks of the little angel (point 6).
As is clear, the spectra indicate the presence of low frequency peaks respectively centred at around 252, 289, and $345 \mathrm{~cm}^{-1}$, which could be attributed to the presence of the cinnabar [21] likely responsible for the intense red colour. Cinnabar is a type of red mercury ore that was generally mixed with an equal amount of burning sulphur to create an expensive red paint used since antique times for cosmetic and decorative purposes. Meanwhile, the band at around $611 \mathrm{~cm}^{-1}$ can be attributed to the presence of iron oxides, while the bands at around 944, 1,315, and $1,404 \mathrm{~cm}^{-1}$ can be ascribed to the presence of organic compounds derived, presumably, from the use of ligands of natural origin. Finally, as Figure $5 \mathrm{~b}$ shows, a $1,083 \mathrm{~cm}^{-1}$ band indicative of the presence of calcite $\left(\mathrm{CaCO}_{3}\right)$ was observed, which was likely related to the preparatory layer or to lightening purposes.

The investigation of the white pigment was carried out in terms of point 4 of the painting (Figure 6), that is, an area of the white band of the soldier standing upright. The spectrum revealed the presence of a strong and sharp Raman band at around $1,050 \mathrm{~cm}^{-1}$, which is characteristic of the lead white $\left(2 \mathrm{PbCO}_{3} \cdot \mathrm{Pb}[\mathrm{OH}]_{2}\right)[22]$ that represents the main white pigment of European oil on canvas paintings. In fact, as reported in a previous study [23], the presence of this band indicated the degradation state of this pigment. Meanwhile, the bands at around $946,1,304$, and $1,404 \mathrm{~cm}^{-1}$ may have been related to the presence of organic components. As with the red pigmented areas, the presence of calcite was indicated by its typical contribution at around $1,084 \mathrm{~cm}^{-1}$. This can be reasonably ascribed to the preparation, even if the combination of calcite with other white pigments, such as lead white, was often used by artists to modify the rheological and optical properties of their paints [24].

With regard to the blue area of Christ's mantle (point 5), the Raman spectrum obtained using the portable instrumentation was completely masked by huge fluorescence, which prevented the molecular identification of the painting materials.

Finally, the broad bands detected at around 1,331 and 1,581 $\mathrm{cm}^{-1}$ in the Raman spectrum for the black fur of the horse (point 7, Figure 7) can be ascribed to the $D$ (disorder) and $G$ (graphitic) bands of amorphous carbon. This occurrence indicates the employment of a carbon-based black pigment, the accurate identification of which via the Raman technique remains fairly difficult.

We now want to focus on a highly interesting point that surfaced from the entire set of spectroscopic results. In short, the

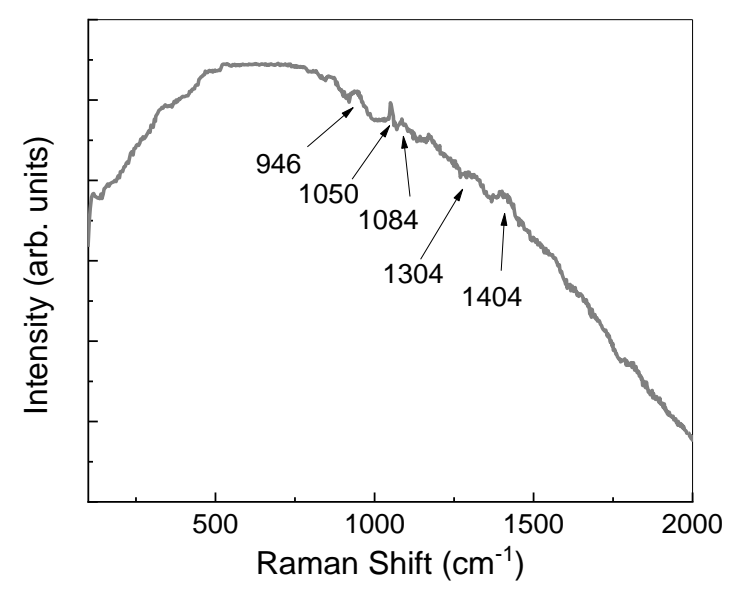

Figure 6. Raman spectrum recorded on a point (point 4) representative of a white pigmented area of The Conversion of St Paul. 


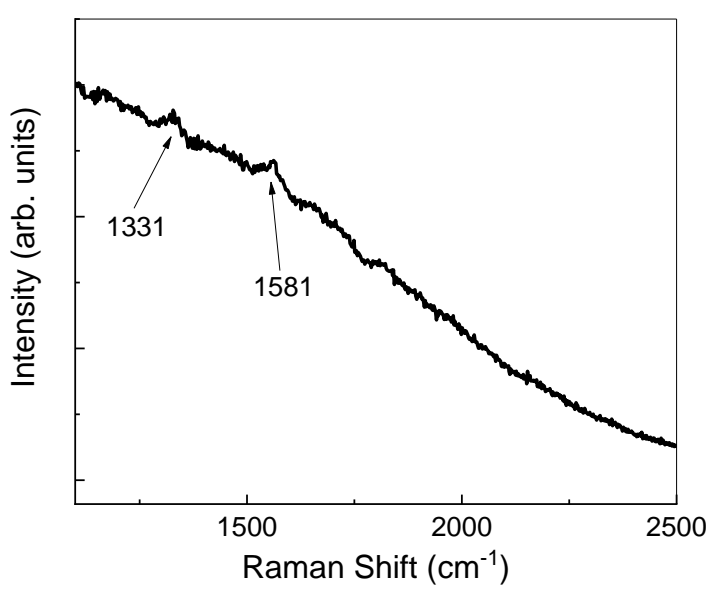

Figure 7. Raman spectrum recorded on a point (namely Point 7) representative of a black pigmented area of The Conversion of St Paul painting.

observation of $\mathrm{Ca}$ in the XRF elemental composition of all the investigated points, along with the observation of calcite in most of the analysed pigmented areas, allow us to hypothesise about the use of typical Maltese globigerina limestone for the preparation of the painting [25]. While we are aware that further petrographical, geochemical and physical analyses are required to unambiguously identify this limestone, the reported information can provide valuable support to ascribing the dating of the painting to the Maltese period of this famous Calabrian painter.

\section{CONCLUSIONS}

In this paper, a non-invasive, in-situ investigation was conducted in relation to The Conversion of St Paul titular painting by the Calabrian artist and Knight, Mattia Preti. The study was specifically aimed at demonstrating the potentialities of the combined use of 2D/3D photogrammetric surveys and spectroscopy (XRF and Raman) techniques to, on the one hand, achieve a reconstruction, and on the other, achieve, at different spatial domains, the identification and characterisation of the pigments used for this wonderful painting, which can be seen at St Paul's Cathedral in Mdina, Malta. The aforementioned methodologies were successfully applied as part of the scientific analysis carried out prior to, during and following the completion of the recent restoration of the painting.

It was demonstrated that the use of photogrammetry in this context can play a key role in the creation of potential bases for research, analysis, and scientific investigations. Furthermore, it allows for obtaining a scaled digital model that can be shared among curators and restaurateurs in order to study the artifact and all its features in detail. Combining the findings obtained at the elemental and molecular levels via XRF and Raman analyses, respectively, we were able to obtain valuable information regarding the artist's palette. Specifically, the main results included that cinnabar and iron oxides were observed in the $\mathrm{red} / \mathrm{reddish}$ pigments, lead white in the white pigment, and carbon black in the black pigment. Furthermore, it was reasonably hypothesised that calcite was used for the preparatory layer of the painting, which allowed us to formulate a hypothesis regarding the dating of The Conversion of St Paul painting to Preti's Maltese period.

This combined approach appears promising, not only for research, preservation and restoration activities but also for improving the promotion, dissemination and accessibility in the field of cultural heritage. This research also serves as a proof of concept and the next goal will be to delve deeper into the investigation of the various other paintings produced by Mattia Preti.

\section{ACKNOWLEDGEMENTS}

The authors thank Monsignor Charles Scicluna, Archibishop of Malta, Monsignor Edgar Vella, Director of Mdina Cathedral Museum, and Monsignor Anton Cassar, Archpriest Mdina Cathedral. We are also grateful to the staff of the Cathedral who allowed us to carry out the measurements, even beyond the normal opening hours. This paper was partially supported by the Joint R\&D Bilater Project entitled 'Noninvasive investigations for enhancing the knowledge and the valorization of the cultural heritage', funded by the University of Malta and the National Research Council of Italy (Biennal Programme 2018-2019).

\section{REFERENCES}

[1] V. Crupi, S. D'Amico, L. Denaro, P. Donato, D. Majolino, G. Paladini, R. Persico, M. Saccone, C. Sansotta, G.V. Spagnolo, V. Venuti, Mobile spectroscopy in archaeometry: some case study, J. Spectrosc. 2018 (2018), Article ID 8295291.

DOI: $10.1155 / 2018 / 8295291$

[2] V. Venuti, B. Fazzari, V. Crupi, D. Majolino, G. Paladini, G. Morabito, G. Certo, S. Lamberto, L. Giacobbe, In situ diagnostic analysis of the XVIII century Madonna della Lettera panel painting (Messina, Italy), Spectrochim. Acta A Mol. Biomol. Spectrosc. 228 (2020), Article ID 117822.

DOI: $\underline{10.1016 / \text { i.saa.2019.117822 }}$

[3] D. Fontana, M.F. Alberghina, R. Barraco, S. Basile, L. Tranchina, M. Brai, A. Gueli, S.O. Troja, Historical pigments characterization by quantitative X-ray fluorescence, J. Cult. Herit. 15 (2014) pp. 266-274.

DOI: $\underline{10.1016 / \text { i.culher.2013.07.001 }}$

[4] G. Burrafato, M. Calabrese, A. Cosentino, A.M. Gueli, S.O. Troja, A. Zuccarello, ColoRaman project: Raman and fluorescence spectroscopy of oil, tempera and fresco paint pigments, J. Raman Spectrosc. 35 (2004) pp. 879-886. DOI: $\underline{10.1002 / \text { irs. } 1229}$

[5] F. Hassani, Documentation of cultural heritage; techniques, potentials, and constraints, Int. Arch. Photogramm. Remote Sens. Spatial Inf. Sci. XL-5/W7 (2015) pp. 207-214. DOI: $10.5194 /$ isprsarchives-XL-5-W7-207-2015

[6] R. Alberti, V. Crupi, R. Frontoni, G. Galli, M.F. La Russa, M. Licchelli, D. Majolino, M. Malagodi, B. Rossi, S.A. Ruffolo, V. Venuti, Handheld XRF and Raman equipment for the in situ investigation of Roman finds in the Villa dei Quintili (Rome, Italy), J. Anal. At. Spectrom. 32 (2017) pp. 117-129.

DOI: $10.1039 / \mathrm{c} 6 \mathrm{ja} 00249 \mathrm{~h}$

[7] V. Crupi, G. Galli, M.F. La Russa, F. Longo, G. Maisano, D. Majolino, M. Malagodi, A. Pezzino, M. Ricca, B. Rossi, S.A. Ruffolo, V. Venuti, Multi-technique investigation of Roman decorated plasters from Villa dei Quintili (Rome, Italy), Appl. Surf. Sci. 349 (2015) pp. 924-930.

DOI: $10.1016 /$ j.apsusc. 2015.05 .074

[8] A. Kriznar, M. del Valme Muñoz, M. Respaldiza, M. Vega, Materials applied in Bernardo Martorelli's painting analysed by portable XRF, Archeosciences-Rev. A 36 (2012) pp. 37-45. DOI: $10.4000 /$ archeosciences.3712

[9] F. Bardelli, G. Barone, V. Crupi, F. Longo, D. Majolino, P. Mazzoleni, V. Venuti, Combined non-destructive XRF and SRXAS study of archaeological artefacts, Anal. Bioanal. Chem. 399 (2011) pp. 3147-3153.

DOI: $10.1007 / \mathrm{s} 00216-011-4718-8$

[10] V. Crupi, B. Fazio, G. Fiocco, G. Galli, M.F. La Russa, M. Licchelli, D. Majolino, M. Malagodi, M. Ricca, S.A. Ruffolo, V. Venuti, Multi-analytical study of Roman frescoes from Villa dei 
Quintili (Rome, Italy), J. Archaeol. Sci.:Rep. 21 (2018) pp. 422-432. DOI: $10.1016 /$ i.jasrep.2018.08.028

[11] S. Guido, G. Mantella, MATTIA PRETI 1613-2013: the masterpieces in the churches of Malta, Miranda Publishers, Sliema, Malta, 2012, ISBN 978-99909-85-46-7.

[12] E. Colica, A. Micallef, S. D'Amico, L.F. Cassar, C. Galdies, Investigating the use of UAV systems for photogrammetric applications: a case study of Ramla bay (Gozo, Malta), Journal of the Malta Chamber of Scientists 5 (2017) pp. 125-131. DOI: 10.7423/XJENZA.2017.2.04

[13] S. D'Amico, V. Crupi, D. Majolino, G. Paladini, V. Venuti, G. Spagnolo, R. Persico, M. Saccone, Multidisciplinary investigations and 3D virtual model at the archeological site of Scifi (Messina,

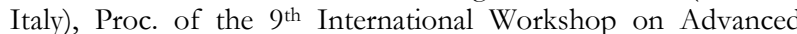
Ground Penetrating Radar - IWAGPR 2017, June 28 - 30 2017, Edinburgh, United Kingdom, pp. 1-4. DOI: $\underline{10.1109 / I W A G P R .2017 .7996085}$

[14] R. Persico, S. D'Amico, L. Matera, E. Colica, C. De Giorgio, A. Alescio, C.V. Sammut, P. Galea, GPR Investigations at St John's Co-Cathedral in Valletta, Near Surf. Geophys. 17 (2019) pp. 213 229.

DOI: $\underline{10.1002 / \mathrm{nsg} .12046}$

[15] T. Schenk, Introduction to Photogrammetry. Department of Civil, Environmental Engineering and Geodetic Science, The Ohio State University, Ohio, 2005.

[16] B. Lafuente, R.T. Downs, H. Yang, N. Stone, The Power of Databases, in: The RRUFF Project, T. Armbruster, R.M. Danisi, W. De Gruyter (editors), Berlin, Germany, 2015, ISBN 978311041710-4, pp. 1-30. DOI: $10.1515 / 9783110417104-003$

[17] I.M. Bell, R.J.H. Clark, P.J. Gibbs, Raman spectroscopic library of natural and synthetic, pigments (pre- $\approx 1850$ AD), Spectrochim. Acta A 53 (1997) pp. 2159-2179. DOI: $10.1016 /$ S1386-1425(97)00140-6
[18] R. Larsen, N. Coluzzi, A. Cosentino, Free XRF spectroscopy database of pigments checker, Int. J. Conserv. Sci. 7 (2016) pp. 659-668.

[19] C. Pelosi, G. Agresti, P. Baraldi, The 'slash of light' in the late religious paintings of Mattia Preti technique and materials, Eur. J. Sci. Theol. 14 (2018) pp. 151-160.

[20] R.L. Feller, Artists' Pigments: A Handbook of their History and Characteristics (Chapter 2), R.L. Feller (editor), Cambridge University Press, Cambridge, 1986, ISBN 978-08946-80-86-1.

[21] P. Dawson, The vibrational spectrum of $\alpha$-mercuric sulphide, Spectrochim. Acta A 28 (1972) pp. 2305-2310. DOI: $10.1016 / 0584-8539(72) 80210-1$

[22] P.C. Gutiérrez-Neiraa, F. Agulló-Rueda, A. Climent-Fonta, C. Garridod, Raman spectroscopy analysis of pigments on Diego Velázquez paintings, Vib. Spectrosc. 69 (2013) pp. 13-20. DOI: $10.1016 /$ i.vibspec.2013.09.007

[23] V.S.F. Muralha, C. Miguel, M.J. Melo, Micro-Raman study of medieval Cistercian 12-13th century manuscripts: Santa Maria de Alcobaça, Portugal, J. Raman Spectrosc. 43 (2012) pp. 1737-1746. DOI: $10.1002 /$ irs.4065

[24] L. de Viguerie, H. Glanville, G. Ducouret, P. Jacquemot, P.A. Dangb, P. Walter, Re-interpretation of the old Masters' practices through optical and rheological investigation: the presence of calcite - Réinterprétation des pratiques des Maîtres anciens par étude optique et rhéologique: la présence de calcite, C. R. Phys. 19 (2018) pp. 543-552. DOI: $\underline{10.1016 / \text { i.crhy.2018.11.003 }}$

[25] D. Hradil, J. Hradilová, G. Lanterna, M. Galeotti, K. Holcová, V. Jaques, P. Bezdička, Clay and alunite-rich materials in painting grounds of prominent Italian masters - Caravaggio and Mattia Preti, Appl. Clay Sci. 185 (2020), Article ID 105412. DOI: $\underline{10.1016 / \text { i.clay.2019.105412 }}$ 